\title{
Metasomatic interactions between chromitite and anorthosite layers in the Sittampundi Complex, South India
}

\author{
VENI SUDARSAN ${ }^{1}$, SAJEEV KRISHNAN ${ }^{1}$ AND BRIAN F. \\ WINDLEY ${ }^{2}$
}

${ }^{1}$ Indian Institute of Science

${ }^{2}$ The University of Leicester

Presenting Author: venisudarsan@iiisc.ac.in

The Archean chromite-layered anorthosite from the Sittampundi Complex, Tamil Nadu, South India, is closely associated with the peraluminous minerals corundum, spinel, sapphirine, sillimanite, staurolite, and högbomite, which are in a matrix of plagioclase. A similar sapphirine-bearing assemblage has prompted many workers to infer ultrahigh-temperature (UHT) metamorphism from the same location. However, a detailed petrological investigation in this study identified lower temperature minerals like Ti-högbomite and staurolite in association with high-temperature minerals like sapphirine and spinel. There are two types of spinel Fe-Mg $(X \mathrm{Mg}=0.4)$ and $\mathrm{Cr}$ rich spinel $\left(\mathrm{Cr}_{2} \mathrm{O}_{3} \quad 12 \mathrm{wt} \%\right)$ in the same sample; nevertheless, chromite is not present in this layer. Spinel grains are mostly present in fractures and grain boundaries of cordierite and plagioclase. Fe-Mg-spinel is associated with Ti-bearing högbomite $\left(\mathrm{TiO}_{2} \sim 5 \mathrm{wt} \%\right)$, which is indistinguishable under transmitted light. Similarly, sapphirine (7:9:3 poly-type) is in equilibrium with Fe-rich staurolite $(X \mathrm{Fe}=0.64)$. Sapphirine and staurolite are mostly along the dihedral grain boundaries of plagioclase $(X \mathrm{An}=0.92)$. Gedrite $(X \mathrm{Mg}=0.65)$ has formed in fractures enclosed by cordierite. Ca-rich plagioclase inclusions are in gedrite, sapphirine, and cordierite, suggesting an earlystage formation of the former. $\mathrm{Ca}$ - amphibole forms inclusions in cordierite with $\mathrm{Cr}_{2} \mathrm{O}_{3}$ up to $\sim 2 \mathrm{wt} \%$. Also, some minerals like sapphirine, corundum, gedrite, sillimanite, högbomite, and staurolite have significant contents of $\mathrm{Cr}_{2} \mathrm{O}_{3}$, indicating chromium mobility due to the close association of chromitite layers in the anorthosite. The textures and mineral chemistry indicate fluid-aided alteration of an anorthosite layer close to chromitite. The fractures and grain boundaries likely facilitated aqueous fluid mobility to produce this rare assemblage. Similar unusual mineral assemblages are identified within the metasomatic sapphirine-bearing rocks of the Fiskenaesset complex, Greenland, and in the Limpopo belt, South Africa. These relations suggest that many interpreted regional UHT metamorphic rocks might rather have formed through local fluiddriven metasomatism. 